\title{
Early Career Researchers between Predatory Publishing and Academic Excellence: The Views and Behaviours of the Millennials
}

\author{
David Nicholas \\ Director, dave.nicholas@ciber-research.com
}

Eti Herman

Consultant, eherman@univ.haifa.ac.il

Anthony Watkinson

Principary consultant, anthony.watkinson@btinternet.com

CIBER Research Ltd, Newbury, Berkshire, RG147RU, UK

Jie Xu

Professor, School of Information Management, xuj@whu.edu.cn

Wuhan University, Wuhan, Hubei 430072, China

Abdullah Abrizah

Full Professor, Department of Library \& Information Science, Faculty of Computer Science \& Information Technology, abrizah@um.edu.my University of Malaya, 50603 Kuala Lumpur, Malaysia

Blanca Rodríguez-Bravo

Full Professor, Biblioteconomía y Documentación, blanca.rodriguez@unileon.es

Universidad de León, 24071 León, Castilla y León, Spain

\section{Cherifa Boukacem-Zeghmouri}

Full Professor, Department of Computer Science, cherifa.boukacem-zeghmouri@univ-lyon1.fr

Université de Lyon, Université Lyon 1, 69100 Villeurbanne, France

\section{Tatiana Polezhaeva}

Head, Laboratory for Library and Communication Studies, publication@mail.tsu.ru

Tomsk State University, 36, Lenin ave., Tomsk 634050, Russian Federation

\section{Marzena Świgon}

Head of Laboratory of Research on Communication and Information Management, marzena.swigon@uwm.edu.pl Uniwersytet Warminsko-Mazurski, 10-719 Olsztyn, Poland

\begin{abstract}
$\mathrm{T}$ he paper draws on evidence of predatory publishing obtained from the four-year-long Harbingers research study of changing scholarly communication attitudes and behavior of early career researchers (ECRs). The project featured longitudinal interviews for its first three years with 116 ECRs researching science and social sciences who came from China, France, Malaysia, Poland, Spain, the UK, and US. The interview data provided the building blocks for a questionnaire survey in the fourth year, which obtained 1,600 responses from a global audience, which included arts and humanities ECRs and those from Russia. These

studies investigated predatory publishing as part of general questioning about scholarly communications. The main findings from the interview study were: 1) ECRs generally do not publish in predatory journals; 2 ) they only allude to them lightly and mainly in the context of open access publishing; and 3) they no longer equate all open access publishing with predatory journals. The questionnaire found that, as in the case of the interviews, complaints that open access represents low quality publishing are diminishing, however, this positivity has been partly offset by increased concerns about the dangers of predatory journals.
\end{abstract}

Keywords: early career researchers; predatory journals; publication strategies; Harbingers study;

scholarly communication
Citation: Nicholas D., Herman E., Watkinson A., Xu J., Abrizah A., Rodriguez-Bravo B., Boukacem-Zeghmouri C. Polezhaeva T., Swigon M. (2021) Early Career Researchers between Predatory Publishing and Academic Excellence: The Views and Behaviours of the Millennials. Foresight and STI Governance, 15(1), 56-65. DOI: 10.17323/2500-2597.2021.1.56.65 


\section{Introduction and Aims}

The Harbingers four-year long study (2016-2019), initially funded by the Publishing Research Consortium, dealt in considerable detail with ECRs' scholarly communication attitudes and behaviors (more than 24 scholarly activities were investigated) and whether these were changing. The first three years involved repeat interviews with nearly 120 ECRs from seven countries and the fourth year featured a questionnaire study which sought to confirm the results of the qualitative data obtained and to follow up on some of the original findings. Much of the findings have been widely published (see reference list) and summaries of the interview and questionnaire stages can, respectively, be found in [Nicholas et al., 2019, 2020].

What we have not done to date though, is to publish what we discovered about predatory publishing and ECRs, and given the considerable rise in predatory journals over the period of the Harbingers study and the amount of research produced about them, literally hundreds of papers published, we wish to contribute our findings to the body of knowledge. We are doing this especially due to the special methodological approach taken, thus: 1) it is the result of studying ECRs in depth, and often personally, for four years; 2) we largely avoided direct questioning about what is a very sensitive and delicate subject, preferring in the interviews to approach the topic broadly or indirectly via discussions about related scholarly activities, such as open access and ethics, and largely through open ended questions in the case of the survey.

\section{Literature Review}

Predatory, questionable, illegitimate, dark, or deceptive publishing are the terms used to refer to fake and scam journals' accepting manuscripts for fees without sufficient quality control, while pretending the very opposite [Frandsen, 2017]. 'Predatory publishing' has become the term most often associated with the phenomenon [Cobey et al., 2018], although as Eriksson \& Helgesson argue, it "unhelpfully bundles misconduct with poor quality" [Eriksson, Helgesson, 2018]. According to Cabells journal blacklist ${ }^{1}$, which screens journals against more than sixty behavioral indicators, the number of predatory journals is currently over 13,000 , a considerable increase from the 8,000 or so found in 2014 [Shen, Björk, 2015]. Plainly then, predatory publishing, representing as it does the penetration of the 'fake news' mentality into the scholarly world, the debasing of scholarly research, a threat to the open science agenda, and the polluting of the scientific record, poses a real challenge to the integrity of science, its credibility, and trustworthiness [Ojala et al., 2020; Shaghaei et al., 2018]. Unsurprisingly, therefore, publishing in a predatory journal is said to render a piece of scholarly work unusable, unfit for citation, indeed, illegitimate, and stigmatized to an extent that puts at risk the reputation of its author [Roberts, 2016], while along the way also besmirching the very jewel in the scholarly communications crown that journals undoubtedly are.

With predatory publishing, thus, clearly running counter to the values widely held to be the very foundations of the scholarly enterprise, there are compelling deterrents against researchers' straying from the straight and narrow in their publishing practices. However, in an environment that sees research productivity as a major yardstick by which the reputation of scholarly success is measured [Blankstein, Wolff-Eisenberg, 2019; Harley et al., 2016; Herman, Nicholas, 2019; Nicholas et al., 2015a, 2015b; Nicholas et al., 2017; van Dalen, Henkens, 2012; Grimes et al., 2018; Memon, 2019], the aforementioned growth in the number of predatory journals, indeed, as we are about to see, with the evidence on the ground, seem to indicate that predatory publishing may be condemned in theory, but accommodated in practice.

Under these circumstances, predatory publishing may be even more of a challenge to young researchers (millennials ${ }^{2}$ ): just making their way, they have to publish to progress, so that the enticements of getting published easily in predatory journals may speak to them even more strongly, especially as, being as yet unversed in the ways of academe, they may be ignorant of the real nature and possible repercussions of the practice. This is of crucial importance, for, as Harbingers research has shown, ECRs ${ }^{3}$ stance toward developing trends in scholarly undertakings promises to lead the way in shaping its future character, indeed, this may very well be instrumental in bringing about an overhaul of the scholarly communications system [Nicholas et al., 2019, 2020]. After all, they are millennials and attempting to re-arrange the world in line with their values and behaviors.

Indeed, young and inexperienced researchers from developing countries typically have been found to have published in predatory journals [Frandsen, 2017; Nobes, Harris, 2019; Shen, Björk, 2015; Truth, 2012; Xia et al., 2015], with the situation in Africa shown to be particularly challenging [Nwagwu, 2015]. According to [Kurt, 2018] "predatory publishers have become another way in which people in the developing world are victimized."

\footnotetext{
https://www2-cabells-com.ezproxy.haifa.ac.il/about-predatory

The term 'millennials', also known as "Generation Y", refers to the cohort of people born or experiencing their formative years just before the turn of the millennium. In its broadest sense millennials are people born between the early 1980s and late 1990s (FEPS - Foundation for European Progressive Studies and ThinkYoung, 2018).

3 Researchers who are generally not older than 35, who either have received their doctorate and are currently in a research position or have been in research positions but are currently doing a doctorate. In neither case are they researchers in established or tenured positions.
} 
However, it is not that simple, for there is also ample evidence to suggest that developing countries and the young and inexperienced are not alone in publishing in predatory journals. In fact, many researchers, regardless of their career experience, geographic location, and disciplinary affiliation, seems to be involved [Perlin et al., 2018]. Thus, predatory publishing is not only an issue in developing countries [Eykens et al., 2019; Moher et al., 2017], specifically with regard to tourism and hospitality [Alrawadieh, 2018]. Indeed, according to the findings of the latter, the socioeconomic and geographical dispersion of the problem may be quite wide: in a sample of 1,907 papers in more than 200 journals, thought likely to be predatory, more than half had authors from highand upper-middle-income countries as defined by the World Bank. By the same token, the results of an investigation into the extent of predatory publishing in Germany showed that 5,000 researchers from German universities, institutes, and federal agencies, including prominent university professors, even a Nobel laureate, have frequently published articles in worthless online scientific journals belonging to pseudo-scientific publishers, often paying exorbitant fees for the privilege [NDR, 2018; Offord, 2018]. In Italy, too, about 5\% of the 46,000 researchers seeking promotion have been found to publish in potential or probable predatory journals on Beall's list ${ }^{4}$ [Bagues et al., 2017]. This is perhaps not as surprising as it seems at first glance, experienced researchers from the developed world, as represented by the faculty of the University of South Denmark [Shaghaei et al., 2018], publish in predatory journals, too, and mainly for the same reasons as researchers from developing countries do: lack of awareness, speed and ease of the publication process, and a chance to get work that has been rejected elsewhere published.

The findings by other researchers [Alrawadieh, 2018; Eykens et al., 2019] also confirm that senior authors are visibly present on the predatory publishing scene, which, as the latter put it, render the assumption that predatory publications are authored mainly by inexperienced authors 'highly doubtful'. For example, experienced researchers in the Brazilian academic system were the ones more likely to publish in predatory journals [Perlin et al., 2018]. For a sample of papers in the field of economics it is shown that more experienced scholars do publish in predatory journals [Wallace, Perri, 2018]. In fact, even the knowledge and influence of predatory journals seems to vary with seniority/experience, as a survey among Austrian dermatologists showed: it was the scientifically active and older participants who were more likely to be familiar with predatory journals [Richtig et al., 2019].
Previous research has shown that predatory publishing is prevalent and is undertaken by junior and senior researchers and those from all parts of the world. However, we need to treat these studies with care. This is because the response rate in these studies is notoriously low (and unrepresentative), a phenomenon that holds true when people are invited to take part in a survey, and arguably even more so when they are asked to agree to be interviewed (see, for example, [Cobey et al., 2019; Demir, 2018; Shaghaei et al., 2018; Shehata, Elgllab, 2018]). The findings in these studies tend to be non-generalizable, too, pertaining as they typically do only to the idiosyncratic circumstances of researchers at a single research institute [Pyne, 2017; Shaghaei et al., 2018], and/or in a limited geographical area [Bagues et al., 2017; Demir, 2018; Mouton, Valentine, 2017; Omobowale et al., 2014; Perlin et al., 2018; Shehata, Elgllab, 2018], and/or a specific discipline or knowledge area [Cobey et al., 2019; Wallace, Perri, 2018].

\section{Methodology}

The first leg of the study, conducted during the period 2016-2018, consisted of a longitudinal, indepth (60-90 minute long) semi-structured interview study, which sought to map the changes in the scholarly communication attitudes and behaviors of 116 science and social science ECRs from China, France, Malaysia, Poland, Spain, the UK, and US in order to establish the extent to which early career researchers are the harbingers of change in the scholarly communications system. The make-up of the samples can be seen in Table 1 .

Interviews were repeated each year for three years and contained more than 60 questions on two dozen scholarly activities and issues, such as social media, ethics, discovery, open access, publishing, and author practices. Changes were calibrated. ${ }^{5}$ There were no direct questions about predatory publishing, instead data was: 1) volunteered during questions on open access publishing, publishing practices, and ethics; 2) prompted where an answer merited it; 3 ) collected by inspecting the CVs of each ECR furnished each year and papers published were crosschecked with Beall's list of predatory journals and publishers (now defunct) to detect predatory publishing.

The qualitative data obtained served to lay the ground for the second, quantitative questionnaire leg of the study (2019). The overarching aim of the questionnaire was to validate the key interview data found (that predatory publishing is associated in the minds of ECRs with open access), update it, and extend the study to a larger, global (including Russia which is also a case study) and a more diverse popu-

\footnotetext{
${ }^{4}$ Now defunct, see https://beallslist.net/

5 The full list and coding sheet can be found at http://ciber-research.eu/download/20160916-Harbingers-research_instruments.pdf.
} 
lation, including the arts and humanities. ${ }^{6}$ The questionnaire reached a population of 1,600 participants worldwide, including Russia, which was not covered by the interview stage. The make-up of the sample can be seen in Table 1.

The questionnaire featured a comprehensive range of questions on scholarly activities, although not as many as covered by the interviews due to time constraints, but it did contain closed and open questions on open access publishing and predatory journals.

As already mentioned, neither in the first, qualitative stage of the study, nor in its second, quantitative stage, were there 'full on' questions about predatory journals for a variety of reasons, among which the methodological problems of probing sensitive issues figured highly. As the studies that examined the incentives and reasons for predatory publishing in the past few years amply prove, the sensitive nature of the topic gives rise to characteristic methodological problems, which we wish to circumvent. Indeed, a common denominator of these studies seems to be their limited scope, stemming from the difficulties of recruiting subjects, be they interviewees or survey respondents. This is unsurprising, of course, for the researchers approached were queried as to their own predatory publishing experience, so that even when anonymity is promised to be guaranteed, people are understandably reluctant to admit that they were either naive enough or unethical enough to publish in a predatory journal.

With respect to the repeat interviews, given the sensitivity of the topic, we explored the topic indirectly

\section{able 1. Composition of Interview and Questionnaire Populations}

\begin{tabular}{|l|c|c|}
\hline \multicolumn{1}{|c|}{ Distribution } & $\begin{array}{c}\text { Interviews } \\
\text { (\%) }\end{array}$ & $\begin{array}{c}\text { Questionnaire } \\
\text { (\%) }\end{array}$ \\
\hline Age & 31 & \\
30 and under & 69 & 39 \\
Over 30 & & 61 \\
\hline Gender & 42 & 48 \\
Female & 58 & 52 \\
Male & & \\
\hline Subject & 0 & 9 \\
Arts and Humanities & & \\
Sciences (physical, biological, & & 57 \\
medical, mathematical, & & \\
computing and agricultural) & 76 & 34 \\
Social sciences & 24 & 4 \\
\hline Geographical & & 17 \\
Africa & 0 & 5 \\
Asia & 22 & 30 \\
Australia/Oceania & 0 & 6 \\
Europe & 54 & 53 \\
Middle East & 0 & 1600 \\
North America & 24 & \\
South \& Central America & 0 & \\
\hline Numbers & 116 & \\
\hline Source: authors. & \multicolumn{2}{|l}{} \\
\hline
\end{tabular}

and in the context as we could not be sure that we would receive informed or truthful answers to questions directly about predatory publishing - after all, not many ECRs, due to their precarious position, would willingly and freely admit to a behavior that, according to [Frandsen, 2019] falls into one of two categories: naïve or deliberately unethical. Therefore, the topic came up as part and parcel of the responses to questions on publishing policies, open access publishing, ethics, and reputation. So this approach meant that the topic was mentioned in the context of reporting on a scholarly activity, rather than resulting from direct and, possibly, leading questions. The questionnaire was informed by the interview data produced, more direct and voluminous quantitative information which was obtained via questions about open access publishing which we had learned from the interviews and this was where predatory journals cropped up.

\section{Findings}

\section{The longitudinal interview leg of the study}

The interview schedule was extremely wide ranging. There were questions about scholarly communications where the topic could have been raised in a broader context especially in connection with open access publishing (e.g., What do you think are the advantages and disadvantages of OA publishing from the point of view of the author? Do you think OA publishing advances science and research, or are you worried that it will dilute the quality of publications, or do you agree/disagree with both propositions?). Ethics was also a topic where predatory journals could have been mentioned (e.g., Do you have a clear understanding of what is generally regarded as ethical and unethical in research and/ or publishing practices or are you uncertain about what is meant by these terms? Are you aware of any unethical publishing/citing behavior among your peers or among those higher in the academic structure?).

In the majority of cases, predatory publishing and journals were only occasionally mentioned, and this might be explained largely by the fact that our ECRs did not publish in them (we inspected their CVs every year to double-check this and only one did). When predatory journals were mentioned, it was mostly in connection with questions about the pros and cons of open access publishing, which is not surprising because open access clearly opened the door for predatory publishing. As the project progressed from 2016 to 2018 it became obvious that ECRs, and especially the scientists among them, were becoming more informed about what open access is and how it could benefit them. They wit-

\footnotetext{
${ }^{6}$ Methodological details of the second leg of the study can be found in [Nicholas et al., 2019] and the questionnaire at http://ciber-research.eu/download/ ECR-questionnaire-for-website-20191129.pdf ).
} 
nessed government attempts to encourage open access publishing, so it was no longer the bogey man that it once was. Indeed, as a consequence, fears that open access journals were in fact predatory lessened, although such concerns never went completely away. This was true for every country, but most markedly so in the case of Chinese and Malaysian ECRs, who, by 2018 , had a very clear understanding of what open access $(\mathrm{OA})$ is. Thus, they exhibited a more neutral and objective attitude toward OA journals, whereas in 2016, unknowledgeable, they regarded most OA journals to be of low quality and predatory. However, despite their increasingly warm sentiments towards OA, in practice not all Chinese ECRs chose this model of publishing, partly because of lingering reputational/predatory concerns, but also, ironically, because they were just more aware of predatory journals, thanks to such sources as Beall's list and the fact that many were of a Chinese origin. Spanish ECRs also told us that they felt more comfortable about publishing in OA journals, as they now knew that they are not always predatory.

Of the seven countries covered, Malaysian ECRs raised the topic of predatory journals most frequently. The topic came up came up in two areas of questioning. The first was open access publishing. Science ECRs made it clear that they did not publish in OA journals or publishers that are listed on Beall's list, for instance, hijacked journals and journals that have misleading metrics since they only went for Web of Science (WoS) indexed journals. 'As long as it is OA is fine, as long as the journal is ISI (Web of Science), reputable and the university will pay the article processing fees but you need to make sure that it is not listed in Beall's list. Not predatory'. 'The ultimate goal of making the results of research freely available around the world is one that is worth fighting for. And has the tendency to increase downloads and citations. But $O A$ is not perfect predatory journals remain a problem'. A knowledgeable Malaysian ECR also lamented the fact that there have been quite a number of predatory journals which are indexed in Scopus and WoS, but listed on Beall's. The second topic area was ethical behavior. In this respect, Malaysians also talked about the consequences of unethical behavior in publishing (detailed in [Abrizah et al., 2019]), with a couple of ECRs mentioning publishers being predatory because they did not provide thorough peer review or honest marketing material. Suspicions in Malaysia were being raised by increased reporting about journals being hijacked, more retraction occurrences, and new types of publication violations were emerging - fake reviews and fake acceptance letters [Abrizah et al., 2019].
By way of contrast, US and UK ECRs provided few comments on predatory journals, indeed, they showed very little interest in ethical matters generally. No doubt they did so believing their scholarly houses were in order. Still, when prompted for a definition of what constitutes unethical behavior, US ECRs mentioned a host of practices: copying others' work and paying someone to do ghost writing; publishing things that are not true; not accurately portraying data; stealing people's ideas or gazumping someone based on presentation; using data more than once in different papers; and anything else that could deceive others. However, interestingly, they did not directly mention publishing in predatory journals, probably, because they have little familiarity with the practice, so it may never occur to them. What also keeps ECRs on the scholarly straight and narrow (and away from predatory journals) is the prescriptive/recommended journal lists, which many governments and ministries produce to ensure that rewards - financial and reputational - are only given to those that publish in top Impact Factor (IF) journals. The Polish list, which minutely records nearly 30,000 journals, is a case in point. Polish researchers obtain a minimum of 20 points if they publish in a prescribed journal, otherwise it is just five points. Indeed, no Polish ECRs published in predatory journals. ${ }^{7}$ Malaysian and Spanish ECRs are similarly constrained in their publishing choices. In consequence, then, on the basis of the interview data, the strong conclusion that can be made is that (our) ECRs do not publish in predatory journals or care greatly about them. This can be ascribed to the fact that many were employed by top research universities, had experienced mentors, and published as part of groups of more senior researchers who kept them in line. Thus, French ECRs (who, incidentally, refer to predatory journals as 'charlatan' or 'Indian' journals - the latter because most of the "SPAM" they receive comes from Indian journals) spoke for all ECRs when they told us that they were always publishing their articles with their Principal Investigator and other members of the lab, and their main concern was to publish in the right journals (not necessarily with the highest IF) for reputation's sake.

So, there is no support here for the contention that millennials are not attracted to predatory publishing. Presumably, then, most of our ECRs did not meet criteria specified in [Frandsen, 2019] that there are two different types of authors who take up the option: the uninformed and the unethical. ECRs at top universities and on top research teams, as the Harbingers ones were, are clearly surrounded by high-

\footnotetext{
Ministry of Science and Higher Education in Poland, Constitution for Science (2019) Komunikat Ministra Nauki i Szkolnictwa Wyższego z dnia 18 grudnia 2019 r. w sprawie wykazu czasopism naukowych i recenzowanych materiałów z konferencji międzynarodowych. http://www.bip.nauka.gov.pl/inne2/ komunikat-ministra-nauki-i-szkolnictwa-wyzszego-z-dnia-18-grudnia-2019-r-w-sprawie-wykazu-czasopism-naukowych-i-recenzowanych-materialowz-konferencji-miedzynarodowych.html
} 
flying, knowledgeable, and experienced colleagues, so they are neither likely to fall prey to unscrupulous publishers nor come up with such low-quality research that their only option is publishing it in scam journals.

\section{The questionnaire leg of the study}

In the questionnaire, as with the interviews, we asked a range of questions about scholarly communications with respect to reading, citing, publishing, authorship, information use and seeking behavior, publishing, peer review, open access publishing, and data and metrics. However, we did not ask a question directly or devote a whole question to predatory journals for the aforementioned reasons. Instead, informed by the interview stage of the connection in ECRs' minds between predatory journals and OA, we adopted a dual approach. First, to ask open-ended questions of those who said they did not publish in OA journals, in order to find out why they did not do so, to see, among other things, whether predatory journals were a factor in this. Second, to ask a closed question on what they thought were the disadvantages of publishing in OA journals, where predatory journals are included on a list of eight reasons why they might not publish in OA. The full list of reasons is provided in Figure 1.

The open-ended responses were coded manually by two different researchers respectively at the same time and then the coding sheets were exchanged and cross-checked by researchers at the primary coding stage after the coding frame and guide were set. This process was repeated in the secondary coding stage. During the whole process, representative responses were quoted and marked for further analysis. The results showed that just $10 \%$ of ECRs felt that they would not publish in OA formats because of predatory or related quality concerns (Table 1). This seems in keeping with the interview findings that OA jour- nals and predatory journals were being de-coupled in their minds. This result needs to be taken in the context of earlier questions in the survey, which found that most ECRs thought there were more and better reasons for publishing OA than not doing so, so just 380 out of 1,600 ECRs answered the question. As in the case of the interviews, Chinese ECRs featured strongly among those that did not trust OA journals and (despite three years later) still grouped them together with predatory journals. They thought they were low quality, lacking credibility, and just generally doubtful. In the words of one ECR: $O A$ journals are unreliable and trustless; they are predatory journals which send me call for paper emails frequently. They usually don't have citations when published. In a number of cases Chinese researchers did not even use the word predatory, although what they were talking about clearly had all the hallmarks of such journals. It was almost as though they could not mention their name because they were so despised. However, in contrast, $\mathrm{Xu}$ et al. [Xu et al., 2020] found in a questionnaire study of mostly young Chinese researchers that perceptions towards OA publishing were more positive, with most respondents no longer thinking that OA journals published poor quality content or were predatory journals. One possible explanation for the different take on this might be that around a quarter of their respondents were recruited via MDPI, an OA publisher platform, and therefore were likely to be more familiar with $\mathrm{OA}$ and have more experience in publishing in OA journals. It could also be down to the fact that respondents were heavily skewed towards engineering and technology and more informed about what open access was and how it could benefit them. This brings us to the difficulties of doing studies in this area and how careful we should be about coming to hard conclusions.

The closed-question approach to predatory journals saw them embedded in a question about the disad-

\section{Figure 1. Main Reason(s) for Not Publishing OA (open-ended question) $(\mathrm{N}=380)$}

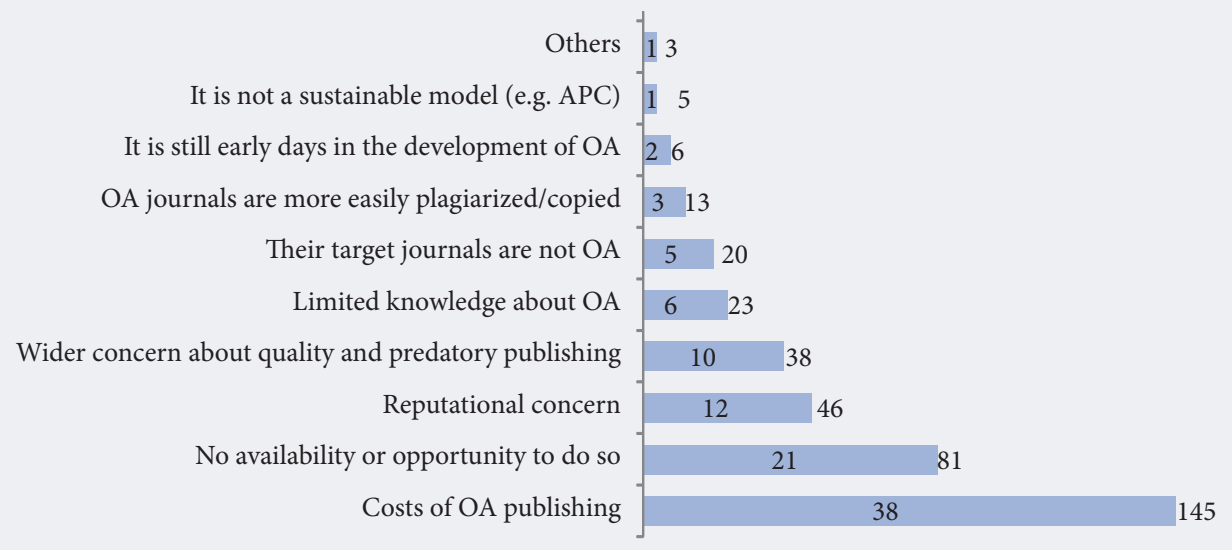

Note: Numbers in the bars are $\%$ and numbers at the end of bars are frequency.

Source: authors. 
vantages of publishing in open access outlets (Fig ure 1) and we sought to test the hypothesis derived from the interview data that there were thought to be too many predatory journals going by the number of emails received. Mean values for these questions are in green and were calculated based on the numeric values of the scale item with not at all being 1 and to a great extent being 5 .

As the open-ended question showed that while the cost of publishing and author processing charges (APCs) are the main concern $(\mathrm{M}=3.97)$ with respect to OA publishing, not so far behind is the belief that there are too many predatory OA journals $(M=3.69)$, with nearly two-thirds of ECRs (62\%) feeling this was somewhat or to a great extent the case. There was an open-ended option also to this question and six ECRs used the facility to leave comments. They provided further evidence of the concerns regarding predatory journals, saying, for instance, that it is hard for newcomers to work out which journals were predatory given the amount of emails they receive from OA journals. While although few in number, the fact that ECRs took the time to express their concern shows the importance they accorded to the predatory problem.

Examining the differences between the case study countries, ECRs from the US believed most $(\mathrm{M}=4.1)$ that the disadvantage of $\mathrm{OA}$ is that there are too many predatory journals among them whilst those from France think so to the least extent $(M=3.7)$. The main significant differences are between the US and France and the US and Poland. US concern was not obvious from the interviews, but then the issue was not pressed so strongly. It may be down to a feeling of general insecurity and, of course, the largest blacklist of journals in the world (Cabells International, see above) is American and sells well there, so, there is evidently some concern in these parts.

To put all this into a broader scholarly context: when presented with a number of advantages of OA pub- lishing, which were thought to be especially beneficial to ECRs for the building of their reputations, it is increased visibility and bigger/wider audiences that proved to be the strongest OA draws. When it came to disadvantages, costs proved to be the biggest one and this was followed closely by the belief that OA journals were tarred with a predatory brush - quite a telling combination. Women tended to be generally more positive about the merits of OA than their male counterparts, although there were no statistical differences between the genders in terms of their views on predatory journals.

\section{Discussion and Conclusions}

From the longitudinal interview study and the accompanying CVs furnished by ECRs, we found that all bar one of our ECRs over the three years had not published in predatory journals. Yes, the pressure to publish was there for most, but not all, however they rarely published in journals they did not know or which were not known to mentors and in many cases these scholars published with their mentors (and when they did so it was not in predatory journals). This was not what we expected because, as we have heard, the literature catalogues numerous instances of young researchers and their older colleagues publishing in predatory journals [Frandsen, 2017]. This is thought to be largely the case because these ECRs came from good universities in developed countries and publish largely as part of groups, where they are mentored and advised. They expressed strong views on having to toe the traditional line to satisfy their principal investigators, co-authors, and mentors. Whether they would have done so without this form of control is something we do not know and will investigate further. Certainly, their precarious job status meant that it would benefit them to publish articles quickly and painlessly, but they also had to play by the accepted scholarly rules. Thus, even if, as millennials, they believe passionately in openness,

able 2. Disadvantages of Open Access Publishing $(\mathbf{N} \approx 1346)$

\begin{tabular}{|c|c|c|c|c|c|c|c|c|c|c|c|c|c|}
\hline & Not & all & Very & ittle & A li & & Som & hat & $\begin{array}{r}\text { To a } \\
\text { ex }\end{array}$ & $\begin{array}{l}\text { reat } \\
\text { nt }\end{array}$ & $\begin{array}{l}\text { do } \\
\mathrm{knc}\end{array}$ & & total \\
\hline & $\mathrm{N}$ & $\%$ & $\mathrm{~N}$ & $\%$ & $\mathrm{~N}$ & $\%$ & $\mathrm{~N}$ & $\%$ & $\mathrm{~N}$ & $\%$ & $\mathrm{~N}$ & $\%$ & \\
\hline Perceived poor quality of OA journals & 199 & 14 & 208 & 15 & 378 & 27 & 404 & 29 & 204 & 15 & 65 & 5 & 1393 \\
\hline $\begin{array}{l}\text { Perceived lower prestige/status of OA } \\
\text { journals }\end{array}$ & 189 & 14 & 225 & 16 & 335 & 24 & 399 & 29 & 240 & 17 & 64 & 5 & 1388 \\
\hline Costs of OA publishing & 79 & 6 & 99 & 7 & 218 & 16 & 325 & 24 & 615 & 46 & 121 & 9 & 1336 \\
\hline $\begin{array}{l}\text { Risks from a career advancing and } \\
\text { reputational point of view }\end{array}$ & 286 & 21 & 275 & 20 & 317 & 24 & 299 & 22 & 167 & 12 & 105 & 8 & 1344 \\
\hline $\begin{array}{l}\text { Possibility that OA journals are more easily } \\
\text { plagiarized }\end{array}$ & 316 & 23 & 261 & 19 & 300 & 22 & 310 & 23 & 163 & 12 & 102 & 8 & 1350 \\
\hline Too many predatory journals & 97 & 8 & 116 & 9 & 276 & 22 & 378 & 30 & 400 & 32 & 189 & 15 & 1267 \\
\hline
\end{tabular}


able 3. ECRs Who Said that the Disadvantage of OA Journals is that Too Many Are Predatory

\begin{tabular}{|c|c|c|c|}
\hline Country case studies & Mean & N & $\begin{array}{c}\text { Standard } \\
\text { Deviation }\end{array}$ \\
\hline China & 3.7 & 217 & 1.0 \\
\hline France & 3.4 & 139 & 1.4 \\
\hline Poland & 3.5 & 123 & 1.4 \\
\hline Russia & 3.6 & 86 & 1.0 \\
\hline Malaysia & 3.9 & 91 & 1.0 \\
\hline USA & 4.1 & 78 & 1.2 \\
\hline UK & 3.6 & 70 & 1.3 \\
\hline Spain & 3.9 & 66 & 1.2 \\
\hline Total & 3.7 & 870 & 1.2 \\
\hline $\begin{array}{l}\text { Note: } \mathrm{p}<0.005, \mathrm{~F}=3.7, \mathrm{df}=7 \\
\text { Source: authors. }\end{array}$ & & \\
\hline
\end{tabular}

sharing, and transparency, this does not extend to publishing in predatory journals.

ECRs not only avoided publishing in predatory journals, they also largely avoided talking about the subject altogether, only occasionally and lightly alluding to it in the interviews and, then, mainly with regard to one scholarly aspect - open access publishing and how it was blemished by predatory journals. However, this was a fear that diminished over the course of the life of the project.

The results of the survey, which sought to 'test' the main interview finding that predatory journals were associated with open access publishing on a bigger and wider population, tell us that it does not mean that the topic is widely disregarded or of little interest. Indeed, ECRs raised concerns voluntarily in open-ended questions when questioned about OA publishing. From this, it is clear, that while complaints that $\mathrm{OA}$ constitutes low quality publishing might be diminishing, this has been partly offset by growing concerns about the increasing numbers of predatory journals and fake research. Concerns were greatest in the US and lowest in France, but this has to be set in context, which is that just $10 \%$ of ECRs felt that they would not publish OA because of predatory or related quality concerns.

So, what does all this tell us? Well, first of all, there is the 'shock of the new' that needs to be taken into account. Thus, while at the beginning of the study much open access publishing was suspect, perceived as predatory, with time (four years) it has become far more acceptable. Predatory publishing, however, has not.

The value of our findings lies in the fact that this is an extremely important area where evidence is thin on the ground and often contradictory, especially as to whether it is young or mature researchers who are the guilty ones. In this study we avoided a direct, potentially intimidating approach to the topic wherever possible; we pulled rather than pushed and, as a consequence, hopefully, have provided an original and fresh view on the topic. You cannot help but come to the conclusion that predatory publishing is little practiced and an irritant rather than a significant threat to the integrity, credibility, and trustworthiness for early career researchers.

Finally, the study's limitations are, firstly, that because of our indirect approach to the topic, researchers were not forced to admit or say anything. They could keep their own counsel in other words. This, however, is countered by the fact that we did not lead them to say anything or force them to lie and the interviews and questionnaire data are very much in line as are the CVs. There is triangulation in other words. There is a second limitation and that is that we only covered relatively wealthy and developed countries. It might well be different in Africa, for instance.

\section{References}

Abrizah A., Shah N.A.K., Nicholas D. (2019) Malaysian early career researchers on the ethics of scholarly publishing. Malaysian Journal of Library \& Information Science, vol. 24, no 1, pp. 75-96. DOI: 10.22452/mjlis.vol21nol.

Alrawadieh Z. (2018) Publishing in predatory tourism and hospitality journals: Mapping the academic market and identifying response strategies. Tourism and Hospitality Research, vol. 20, no 1, pp. 72-81. DOI: 10.1177/1467358418800121.

Bagues M.F., Sylos Labini M., Zinovyeva N. (2017) A walk on the wild side: An investigation into the quantity and quality of 'predatory' publications in Italian academia (LEM Working Paper Series 2017/01). Available at: http://hdl.handle. net/10419/174551, accessed 16.08.2020.

Blankstein M., Wolff-Eisenberg C. (2019) U.S. faculty survey 2018, Ithaka S+R, New York. DOI: 10.18665/sr.311199. Available at: https://sr.ithaka.org/wp-content/uploads/2019/03/SR-Report-US-Faculty-Survey-2018-04122019.pdf, accessed 16.08.2020.

Cobey K.D., Grudniewicz A., Lalu M.M., Rice D.B., Raffoul H., Moher D. (2019) Knowledge and motivations of researchers publishing in presumed predatory journals: A survey. BMJ Open, vol. 9, no 3, art. e026516. DOI: 10.1136/ bmjopen-2018-026516.

Cobey K.D., Lalu M.M., Skidmore B., Ahmadzai N., Grudniewicz A., Moher D. (2018) What is a predatory journal? A scoping review. F1000Research, vol. 7, art. 1001. DOI: 10.12688/f1000research.15256.2. 
Demir S.B. (2018) Predatory journals: Who publishes in them and why? Journal of Informetrics, vol. 12, no 4, pp. 1296-1311. DOI: $10.1016 /$ j.joi.2018.10.008.

Eriksson S., Helgesson G. (2018) Time to stop talking about 'predatory journals'. Learned Publishing, vol. 31, no 2, pp. 181-183. DOI: 10.1002/leap.1135.

Eykens J., Guns R., Rahman A.J., Engels T.C. (2019) Identifying publications in questionable journals in the context of performance-based research funding. PloS one, vol. 14, no 11, art. e0224541. Available at: https://doi.org/10.1371/journal. pone.0224541, accessed 12.08.2020.

Frandsen T.F. (2017) Are predatory journals undermining the credibility of science? A bibliometric analysis of citers. Scientometrics, vol. 113, no 3, pp. 1513-1528. DOI: 10.1007/s11192-017-2520-x.

Frandsen T.F. (2019) Why do researchers decide to publish in questionable journals? A review of the literature. Learned Publishing, vol. 32, no 1, pp. 57-62. DOI: 10.1002/leap.1214.

Grimes D.R., Bauch C.T., Ioannidis J.P.A. (2018) Modelling science trustworthiness under publish or perish pressure. Royal Society Open Science, vol. 5. Available at: https://doi.org/10.1098/rsos.171511, accessed 16.05.2020.

Harley Y.X., Huysamen E., Hlungwani C. Douglas T. (2016) Does the DHET research output subsidy model penalise high-citation publication? A case study. South African Journal of Science, vol. 112, no 5/6, pp. 114-117. DOI: 10.17159/ sajs.2016/20150352.

Herman E., Nicholas D. (2019) Scholarly reputation building in the digital age: An activity-specific approach. Review article. El Profesional de la Información (EPI), vol. 28, no 1, art. e280102. DOI: 10.3145/epi.2019.ene.02. Available at: https://recyt. fecyt.es/index.php/EPI/article/download/epi.2019.ene.02/42164, accessed 06.07.2020.

Kurt S. (2018) Why do authors publish in predatory journals? Learned Publishing, vol. 31, no 2, pp. 141-147. DOI: 10.1002/ leap. 1150 .

Memon A.R. (2019) Revisiting the term predatory open access publishing // Journal of Korean Medical Science, vol. 34, no 13, art. e99. DOI: 10.3346/jkms.2019.34.e99. Available at: https://www.ncbi.nlm.nih.gov/pmc/articles/PMC6449603/, accessed 21.06.2020.

Moher D., Shamseer L., Cobey K.D., Lalu M.M., Galipeau J., Avey M.T., Ahmadzai N., Alabousi M., Barbeau P., Beck A., Daniel R., Frank R., Ghannad M., Hamel C., Hersi M., Hutton B., Isupov I., McGrath T.A., McInnes M.D.F., Page M.J., Pratt M., Pussegoda K., Shea B., Srivastava A., Stevens A., Thavorn K., van Katwyk S., Ward R., Wolfe D., Yazdi F., Yu A.M., Ziai, H. (2017) Stop this waste of people, animals and money. Nature, vol. 549, no 7670, pp. 23-25. DOI:10.1038/549023a.

Mouton J., Valentine A. (2017) The extent of South African authored articles in predatory journals. South African Journal of Science, vol. 113, no 7-8, pp. 1-9. DOI: 10.17159/sajs.2017/20170010.

NDR (2018) More than 5,000 German scientists have published papers in pseudo-scientific journals. Available at: https:// www.ndr.de/der_ndr/presse/More-than-5000-German-scientists-have-published-papers-in-pseudo-scientificjournals,fakescience178.html, accessed 31.08.2020.

Nicholas D., Herman E., Jamali H., Bravo B. R., Boukacem-Zeghmouri C., Dobrowolski T., Pouchot S. (2015) New ways of building, showcasing, and measuring scholarly reputation. Learned Publishing, vol. 28, no 3, pp. $169-183$. DOI: $10.1087 / 20150303$.

Nicholas D., Jamali H.R., Herman E., Watkinson A., Abrizah A., Rodríguez-Bravo B., Boukacem-Zeghmouri C., Xu J., Świgoń M., Polezhaeva T. (2020) A global questionnaire survey of the scholarly communication attitudes and behaviours of early career researchers. Learned Publishing (in press, first published online 30.01.2020). Available at: https://doi.org/10.1002/ leap.1286, accessed 23.08.2020.

Nicholas D., Rodríguez-Bravo B., Watkinson A., Boukacem-Zeghmouri C., Herman E., Xu J., Abrizah A., Świgoń M. (2017) Early career researchers and their publishing and authorship practices. Learned Publishing, vol. 30, no 3, pp. $205-217$. DOI: 10.1002/leap.1102.

Nicholas D., Watkinson A., Boukacem-Zeghmouri C., Rodríguez-Bravo B., Xu J., Abrizah A., Świgoń M., Clark D., Herman E. (2019) So, are early career researchers the harbingers of change? Learned Publishing, vol. 32, no 3, pp. $237-247$. DOI: $10.1002 /$ leap.1232.

Nicholas D., Watkinson A., Jamali H.R., Herman E., Tenopir C., Volentine R., Allard S., Levine K. (2015) Peer review: Still king in the digital age. Learned Publishing, vol. 28, no 1, pp. 15-21. DOI: 10.1087/20150104.

Nobes A., Harris S. (2019) Open Access in low-and middle-income countries: attitudes and experiences of researchers. Emerald Open Research, no 1 (17). Available at: https://doi.org/10.35241/emeraldopenres.13325.1, accessed 11.08.2020.

Nwagwu W.E. (2015) Counterpoints about predatory open access and knowledge publishing in Africa. Learned Publishing, vol. 28, no 2, pp. 114-122. DOI: 10.1087/20150205.

Offord C. (2018) German scientists frequently publish in predatory journals. The Scientist, 19.07.2018. Available at: https://www. the-scientist.com/news-opinion/german-scientists-frequently-publish-in-predatory-journals-64518, accessed 15.06.2020.

Ojala M., Reynolds R., Johnson K.G. (2020) Predatory Journal Challenges and Responses. The Serials Librarian, vol. 78, no 1-4, pp. 98-103. DOI: 10.1080/0361526X.2020.1722894.

Omobowale A.O., Akanle O., Adeniran A.I., Adegboyega K. (2014) Peripheral scholarship and the context of foreign paid publishing in Nigeria. Current Sociology, vol. 62, no 5, pp. 666-684. DOI: 10.1177/0011392113508127. 
Perlin S., Imasato T., Borenstein, D. (2018) Is predatory publishing a real threat? Evidence from a large database study. Scientometrics, vol. 116, no 1, pp. 255-273. DOI:10.1007/s11192-018-2750-6.

Pyne D. (2017) The rewards of predatory publications at a small business school. Journal of Scholarly Publishing, vol. 48, no 3, pp. 137-160. DOI: 10.3138/jsp.48.3.137.

Richtig G., Richtig M., Hoetzenecker W., Saxinger W., Lange-Asschenfeldt B., Steiner A., Strohal R., Posch C., Bauer J.W., Müllegger R.R., Deinlein T. (2019) Knowledge and influence of predatory journals in dermatology: A Pan-Austrian Survey. Acta Dermato-Venereologica, vol. 99, no 1-2, pp. 58-62. DOI: 10.2340/00015555-3037.

Roberts J. (2016) Predatory journals: Illegitimate publishing and its threat to all readers and authors. Journal of Sexual Medicine, vol. 13, no 12, pp. 1830-1833. DOI: 10.1016/j.jsxm.2016.10.008.

Shaghaei N., Wien C., Holck J., Thiesen A.L., Ellegaard O., Vlachos E., Drachen T. (2018) Being a deliberate prey of a predator: Researchers' thoughts after having published in predatory journal. LIBER Quarterly, vol. 28, no 1, pp. 1-17. DOI: 10.18352/ lq.10259.

Shehata A.M.K., Elgllab M.F.M. (2018) Where Arab social science and humanities scholars choose to publish: Falling in the predatory journals trap. Learned Publishing, vol. 31, no 3, pp. 222-229. DOI: 10.1002/leap.1167.

Shen C., Björk B.C. (2015) 'Predatory'open access: A longitudinal study of article volumes and market characteristics. BMC Medicine, vol. 13, no 1, art. 230. DOI: 10.1186/s12916-015-0469-2. Available at: https://bmcmedicine.biomedcentral.com/ articles/10.1186/s12916-015-0469-2, accessed 16.04.2020.

Truth F. (2012) Pay big to publish fast: Academic journal rackets. Journal for Critical Education Policy Studies, vol. 10, no 2, pp. 54-105.

van Dalen H.P., Henkens K. (2012) Intended and Unintended Consequences of a Publish-or-Perish Culture: A Worldwide Survey (CentER Discussion Paper Series 2012-003). DOI: 10.2139/ssrn.1983205. Available at: http://dx.doi.org/10.2139/ ssrn.1983205, accessed 31.08.2020.

Wallace F.H., Perri T.J. (2018) Economists behaving badly: Publications in predatory journals. Scientometrics, vol. 115, no 2, pp. 749-766. DOI: 10.1007/s11192-018-2690-1.

Xia J., Harmon J.L., Connolly K.G., Donnelly R.M., Anderson M.R., Howard H.A. (2015) Who publishes in 'predatory' journals? Journal of the Association for Information Science \& Technology, vol. 66, no 7, pp. 1406-1417. DOI:10.1002/ asi.23265.

Xu J., He C., Su J., Zeng Y., Wang Z., Fang F., Tang W. (2020) Chinese researchers' perceptions and use of open access journals: Results of an online questionnaire survey. Learned Publishing (in press, first published online 02.03.2020). Available at: https://doi.org/10.1002/leap.1291, accessed 29.08.2020. 